Provided for non-commercial research and education use. Not for reproduction, distribution or commercial use.

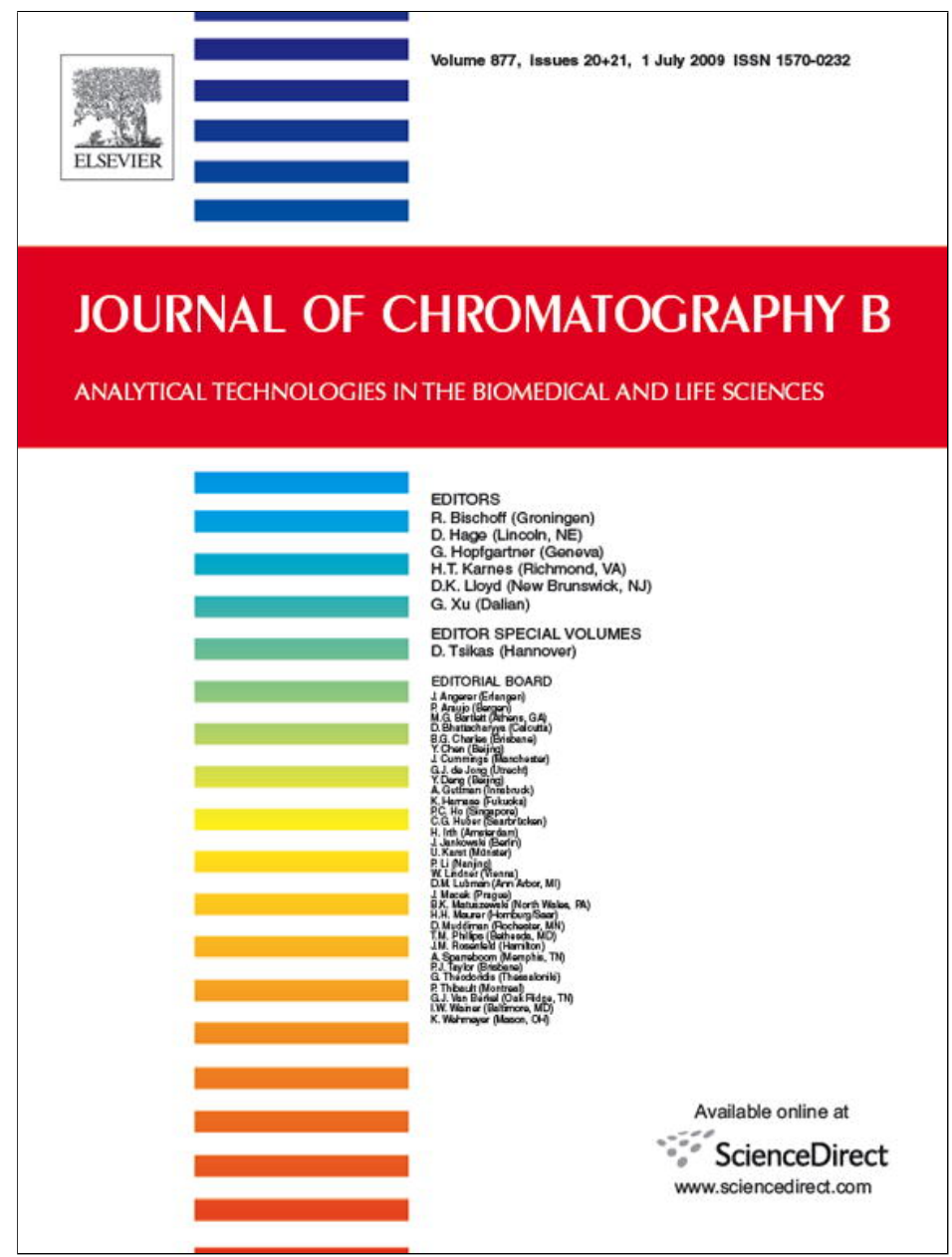

This article appeared in a journal published by Elsevier. The attached copy is furnished to the author for internal non-commercial research and education use, including for instruction at the authors institution and sharing with colleagues.

Other uses, including reproduction and distribution, or selling or licensing copies, or posting to personal, institutional or third party websites are prohibited.

In most cases authors are permitted to post their version of the article (e.g. in Word or Tex form) to their personal website or institutional repository. Authors requiring further information regarding Elsevier's archiving and manuscript policies are encouraged to visit:

http://www.elsevier.com/copyright 


\title{
Improved separation and quantification of neutral and polar lipid classes by HPLC-ELSD using a monolithic silica phase: Application to exceptional marine lipids
}

\author{
Martin Graeve*, Dieter Janssen \\ Alfred Wegener Institute for Polar and Marine Research, Ecological Chemistry, Am Handelshafen 12, 27570 Bremerhaven, Germany
}

\section{A R T I C L E I N F O}

\section{Article history:}

Received 16 December 2008

Accepted 5 May 2009

Available online 13 May 2009

\section{Keywords:}

Marine lipids

Lipid classes

Monolithic column

HPLC-ELSD

Zooplankton

\begin{abstract}
A B S T R A C T
An improved HPLC method is presented, which allows separation and quantification of a broad range of lipid classes of marine zooplankton with special regard to neutral lipids. Marine zooplankton species often produce high amounts of exceptional lipids, especially at high latitudes, in order to cope with the harsh environmental conditions and strong seasonality in food supply. Major neutral lipid classes are wax esters, triacylglycerols, diacylglycerol ethers, free fatty alcohols and sterols. Neutral and polar lipids were separated and identified on a monolithic silica column (Chromolith ${ }^{\circledR}$ Performance-Si) using high performance liquid chromatography (HPLC) with an evaporative light scattering detector (ELSD). The method resolves a broad spectrum of lipids, varying in polarity from squalene to lysophosphatidylcholine in a single run. The total run time was $35 \mathrm{~min}$ including column re-equilibration. The calibration was made at levels of $0.1-60 \mu \mathrm{g}$ lipid/injection, but a 10-15-fold greater amount can be injected if single lipid classes need to be separated, e.g. for further determination of individual fatty acids. The method was applied to representative Arctic zooplankton species (copepods, pteropods, euphausiids and ctenophores) that are known to biosynthesize in particular neutral lipids like diacylglycerol ethers and free fatty alcohols.

(C) 2009 Elsevier B.V. All rights reserved.
\end{abstract}

\section{Introduction}

Marine zooplanktonic organisms can accumulate very large amounts of lipids and thus play a key role in the marine food web due to the transfer of energy from unicellular algae to higher trophic levels such as fish, seabirds and whales. Lipids in marine zooplankton are highly diverse and complex and exhibit various special characteristics as indicated by their polarity. They can comprise of considerable amounts of neutral lipids, consisting of wax esters, triacylglycerols, free fatty acids, and diacylglycerol ethers as well as free fatty alcohols and sterols [1]. Beside these storage lipids, phospholipids are key components of bio-membranes, consisting mainly of phosphatidylcholine and phosphatidylethanolamine with large amounts of the important omega-3 fatty acids, 22:6(n-3) (DHA) and 20:5(n-3) (EPA) [2].

The chromatographic separation of lipid classes is based on well established methods, i.e. column chromatography, thin layer chromatography with densitometric or flame ionization detection [3-6]. Christie [7] and Homan and Anderson [8] presented methods for the separation of lipid classes applying an HPLC system equipped with a pure silica gel column and light scattering detection (ELSD). On this

\footnotetext{
* Corresponding author. Tel.: +49 4714831 1427; fax: +49 47148312115.

E-mail address: martin.graeve@awi.de (M. Graeve).
}

conventional normal phase (NP) column they achieved a comprehensive separation of up to 16 lipid classes in one single run. Further development was achieved with a polyvinyl alcohol-bonded phase (PVA), that was used for the separation of sphingolipids, glycoglycerolipids, phospholipids and the more polar lipid constituents of marine particulate matter $[9,10]$. Other authors presented methods for the separation of neutral and polar lipid classes using diol-NP columns $[11,12]$. They demonstrated excellent separations either for neutral lipids or polar lipids. However, the full range of lipid classes could not be separated in a single run. Another property of these conventional columns is their pressure limit. The pressure drop increases with smaller particle size which, however, reduces eddy diffusion and results in greater column efficiency [13-15]. In recent years, monolithic silica gel columns are used increasingly more often for the separation of lipids, and several applications have been published [16,17]. These columns have attracted considerable attention in HPLC due to its simple preparation procedure, unique properties and excellent performance $[13,18]$. They differ from classical silica columns in consisting of a silica rod instead of particles. The very high porosity of the stationary phase $(2 \mu \mathrm{m}$ macropore and $13 \mathrm{~nm}$ mesopore size) allows chromatography with much lower back-pressure than on conventional columns, and therefore, flow rates up to $9 \mathrm{~mL} / \mathrm{min}$ are possible.

We here present an improved HPLC-ELSD method, which permits the separation and quantification of lipid classes ranging from 
squalene with a very low polarity to highly polar lysophosphatidylcholine, using a monolithic silica column $(100 \mathrm{~mm} \times 4.6 \mathrm{~mm}$ I.D. $)$. This method yields in improved separation performance for neutral lipid classes, which are highly variable and abundant in marine zooplankton.

\section{Materials and methods}

\subsection{Materials}

Squalene, wax ester, nonadecanoic acid methylester (FAME) (Sigma-Aldrich, USA), trioleate, oleyl alcohol, cholesterol, palmitic acid, cerebrosids, phosphatidylethanolamine, phosphatidylinositol, phosphatidylserine, cardiolipine, phosphatidylcholine, lysophosphatidylcholine (Larodan, USA), diacylglycerol ethers (1-O-alkyldiacyl-sn-glycerol; extracted from shark liver oil). Solvents: isooctane, ethyl acetate, acetone, 2-propanol (all Merck, Darmstadt, HPLC grade) and de-ionized water (milli-Q water).

\subsection{Chromatographic equipment}

The LaChrom Elite HPLC system consists of an L2130 LC pump, an L2200 injector, an L2300 column oven set at $40^{\circ} \mathrm{C}$ (VWR, Darmstadt, Germany), and a Sedex 75 evaporative light scattering detector (Sedere, France) set to gain 7, drift tube temperature of $40^{\circ} \mathrm{C}$ and 3.5 bar internal nitrogen pressure. Data acquisition was performed using LaChrom Elite software (3.1.7) (VWR, Darmstadt, Germany). Lipid classes were separated on a Chromolith ${ }^{\circledR}$ Performance-Si $(100 \times 4.6 \mathrm{~mm}$ I.D. $)$ column $(\mathrm{VWR})$ using a gradient programme (Table 1). The specification of the column was given by a monolithic macropore size of $2 \mu \mathrm{m}$ and a mesopore size of $13 \mathrm{~nm}$ (130 $)$ with a total porosity of $>80 \%$.

\subsection{Chromatographic method}

The separation of lipid classes was achieved with a gradient programme (Table 1). A combination of three solvent mixtures was used: Eluent A consisted of isooctane:ethylacetate $(99.8: 0.2, \mathrm{v} / \mathrm{v})$, eluent $B$ was a mixture of acetone and ethyl acetate $(2: 1, \mathrm{v} / \mathrm{v})$ containing acetic acid $(0.02 \%(\mathrm{v} / \mathrm{v}))$ and eluent C 2-propanol-water $(85: 15, v / v)$ (with acetic acid and ethanolamine, each $0.05 \%(\mathrm{v} / \mathrm{v}))$. Gradient programme and mobile phase were essentially chosen after Homan and Anderson [8]. Dichloromethane and tetrahydrofu-

Table 1

Ternary gradient mobile phase composition.

\begin{tabular}{lrrrl}
\hline \multirow{2}{*}{ Time (min) } & \multicolumn{2}{l}{ Percent solvent } & Flow-rate $(\mathrm{mL} / \mathrm{min})$ \\
\cline { 2 - 4 } & $\mathrm{A}$ & $\mathrm{B}$ & $\mathrm{C}$ & \\
\hline 0.0 & 100 & 0 & 0 & 0.0 \\
0.1 & 100 & 0 & 0 & 1.4 \\
1.5 & 100 & 0 & 0 & 1.4 \\
1.6 & 97 & 3 & 0 & 1.4 \\
6.0 & 94 & 6 & 0 & 1.4 \\
8.0 & 50 & 50 & 0 & 1.4 \\
8.1 & 46 & 39 & 15 & 1.4 \\
14.0 & 43 & 30 & 27 & 1.4 \\
14.1 & 43 & 30 & 27 & 1.4 \\
18.0 & 40 & 0 & 60 & 1.4 \\
23.0 & 40 & 0 & 60 & 1.4 \\
23.1 & 0 & 100 & 0 & 3.0 \\
25.0 & 0 & 100 & 0 & 3.0 \\
25.1 & 100 & 0 & 0 & 3.0 \\
35.0 & 100 & 0 & 0 & 3.0 \\
35.1 & 100 & 0 & 0 & 0 \\
\hline A & 00 & 0 & 0
\end{tabular}

A, isooctane:ethyl acetate $(99.8: 0.2, \mathrm{v} / \mathrm{v})$; B, acetone:ethyl acetate $(2: 1, \mathrm{v} / \mathrm{v})$ contain ing $0.02 \%$ acetic acid $(\mathrm{v} / \mathrm{v})$; C, 2-propanol:water $(85: 15, \mathrm{v} / \mathrm{v})$, containing acetic acid and ethanolamine, each $0.05 \%(\mathrm{v} / \mathrm{v})$. ran were replaced by ethyl acetate, because of the cladding material PEEK [18]. Thus, no chlorinated hydrocarbons were utilized. The initial eluent (isooctane modified with $0.2 \%$ ethyl acetate) was selected because of its low polarity to separate squalene, sterolesters and wax esters, which eluted after 1.4-3.0 min. Separation of diacylglycerol ethers and triacylglycerols was achieved with a slow increase of solvent B from $3 \%$ to $6 \%$ during 6.0 min after the initial period of $1.6 \mathrm{~min}$ of the gradient programme. The final proportion of $50 \%$ solvent $B$ was found to be optimal for the separation of the remaining neutral lipids. All neutral lipids fully eluted after $10 \mathrm{~min}$. With increasing proportions of eluent $\mathrm{C}$ the polar lipids were separated (Table 1). As final step a thorough flush-out of polar impurities and water was achieved, first with solvent $B(1.9 \mathrm{~min})$ followed by solvent $A(10 \mathrm{~min})$ at $3 \mathrm{~mL} / \mathrm{min}$. The total run time between injections was $35 \mathrm{~min}$.

Stock solutions ( $5 \mathrm{mg} / \mathrm{mL}$ ) of each standard compound were prepared for calibration of the detector response. They were combined to two standard mixtures. The first consisted of $0.1-0.2 \mathrm{mg} / \mathrm{mL}$ of each neutral lipid (NL) and the second of $0.2-0.4 \mathrm{mg} / \mathrm{mL}$ of each phospholipid (PL). Calibration curves for the lipid classes were obtained by injecting different volumes from 5 to $60 \mu \mathrm{L}$ of neutral and polar lipids dissolved in solvent $\mathrm{A}$. This yields in total amounts from 0.5 to $30 \mu \mathrm{g}$ for NL and 1.0 to $60 \mu \mathrm{g}$ for PL. The reproducibility of the method was evaluated by replicate injections of standard solutions (Table 2). Lipids were kept in dichloromethane:methanol $(2: 1, \mathrm{v} / \mathrm{v})$ and stored at $-20^{\circ} \mathrm{C}$. This solvent mixture was only used for injection volumes up to $2 \mu \mathrm{L}$. If larger volumes have to be injected, samples were evaporated and dissolved in solvent $A$ just before HPLC analysis.

\subsection{Sample preparation}

Different zooplankton species were collected at various sampling sites in Kongsfjorden (Spitsbergen) during spring 2006 and 2007. Live specimens were transported in $10 \mathrm{~L}$ plastic buckets filled with cold seawater to the nearby laboratory in NyÅlesund. Specimens were dropped into glass vials and stored at $-80^{\circ} \mathrm{C}$ until extraction with dichloromethane:methanol $(2: 1, \mathrm{v} / \mathrm{v})$.

Animals were homogenized and extracted after Folch et al. [19] 3 times with $4 \mathrm{~mL}$ dichloromethane:methanol (2:1, v/v) using a Potter homogenizer (Braun, Melsungen, Germany). The solvent was washed with $4 \mathrm{~mL} 0.88 \% \mathrm{KCl}$ solution before the mixture was centrifuged at low speed $(2000 \mathrm{rpm})$. The lipid containing organic phase was separated and evaporated under a gentle stream of nitrogen. The lipid extract was re-dissolved in dichloromethane:methanol $(2: 1, \mathrm{v} / \mathrm{v})$ to a known concentration and taken for analysis. The extracts were kept at $-20^{\circ} \mathrm{C}$ transported frozen to Bremerhaven.

\section{Results and discussion}

Monolithic columns offer new possibilities for faster separation and/or increasing column efficiencies, while avoiding the pressure constraint to a great extent. The high external porosity, uniformity of through-pores, and large (through-pore size) to (skeleton size) ratios can lead to a much higher permeability of monolithic silica columns than that of a column packed with particles of similar column efficiency. Monolithic silica materials typically posses about $60 \%$ external porosity, and $85 \%$ total porosity, which is much higher than those of particle-packed columns with about $20 \%$ porosity. The resulting hydraulic resistance is therefore much lower and enables the maintenance of higher mobile phase flow rates $[18,20]$. An improved resolution, especially for neutral lipids was achieved with slight changes of the nonpolar solvent and a modified solvent programme (Table 1 ) This is a clear advantage compared to 
Table 2

Reproducibility of detector response and retention times of selected lipid standards (1.0 and $4.0 \mu \mathrm{g} / \mu \mathrm{L}$ ) injected 10 times.

\begin{tabular}{|c|c|c|c|c|c|c|c|}
\hline \multirow[t]{2}{*}{ Lipid classes } & \multirow[t]{2}{*}{ Amount $(\mu \mathrm{g} / \mu \mathrm{L})$} & \multicolumn{3}{|l|}{ Peak area } & \multicolumn{3}{|c|}{ Retention time (min) } \\
\hline & & Mean & SD & $\%$ RSD & Mean & SD & \%RSD \\
\hline \multirow[t]{2}{*}{ WE } & 1.0 & $1,226,214$ & 53,481 & 4.4 & 2.1 & 0.02 & 1.0 \\
\hline & 4.0 & $8,207,105$ & 218,110 & 2.7 & 2.4 & 0.01 & 0.2 \\
\hline \multirow[t]{2}{*}{ TAG } & 1.0 & $1,787,963$ & 56,630 & 3.2 & 5.2 & 0.01 & 0.3 \\
\hline & 4.0 & $10,831,434$ & 481,779 & 4.4 & 5.5 & 0.01 & 0.5 \\
\hline \multirow[t]{2}{*}{ Sterols } & 1.0 & 588,212 & 18,826 & 3.2 & 6.9 & 0.03 & 0.2 \\
\hline & 4.0 & $5,823,414$ & 210,236 & 3.6 & 7.2 & 0.01 & 0.2 \\
\hline \multirow[t]{2}{*}{ PE } & 1.0 & $1,040,627$ & 20,084 & 1.9 & 13.8 & 0.03 & 1.2 \\
\hline & 4.0 & $9,469,480$ & 364,835 & 3.9 & 14.1 & 0.16 & 1.2 \\
\hline \multirow[t]{2}{*}{ PC } & 1.0 & $1,371,655$ & 64,129 & 4.7 & 17.7 & 0.02 & 0.1 \\
\hline & 4.0 & $9,271,785$ & 587,712 & 6.3 & 18.0 & 0.02 & 0.1 \\
\hline
\end{tabular}

PVA stationary phases, the polar properties of which make separation of different non-polar lipids such as hydrocarbons, wax esters and sterol esters impossible [9]. A disadvantage of monolithic columns is their lack of mechanical stability because most polymers swell or shrink in organic solvents. Because of the column cladding material PEEK, which is protecting the monolith, HPLC solvents should not exceed a maximum portion of $5 \%$ dichloromethane or chloroform. When monolithic columns are prepared in a mold, bare silica rods must be covered by cladding material such as PTFE or PEEK in order to protect the monolith $[16,18]$ and for this reason, chloroform, dichloromethane or tetrahydrofuran were replaced by ethyl acetate $[7,8,18]$. Similar considerations concern the injection of samples. If samples of more than of $2 \mu \mathrm{L}$ have to be injected, dichloromethane/methanol has to be replaced by solvent A (isooctane-ethyl acetate $(99.8: 0.2, \mathrm{v} / \mathrm{v})$ ). Then up to $60 \mu \mathrm{L}$ of lipid extract can be injected without change of retention times, espe-
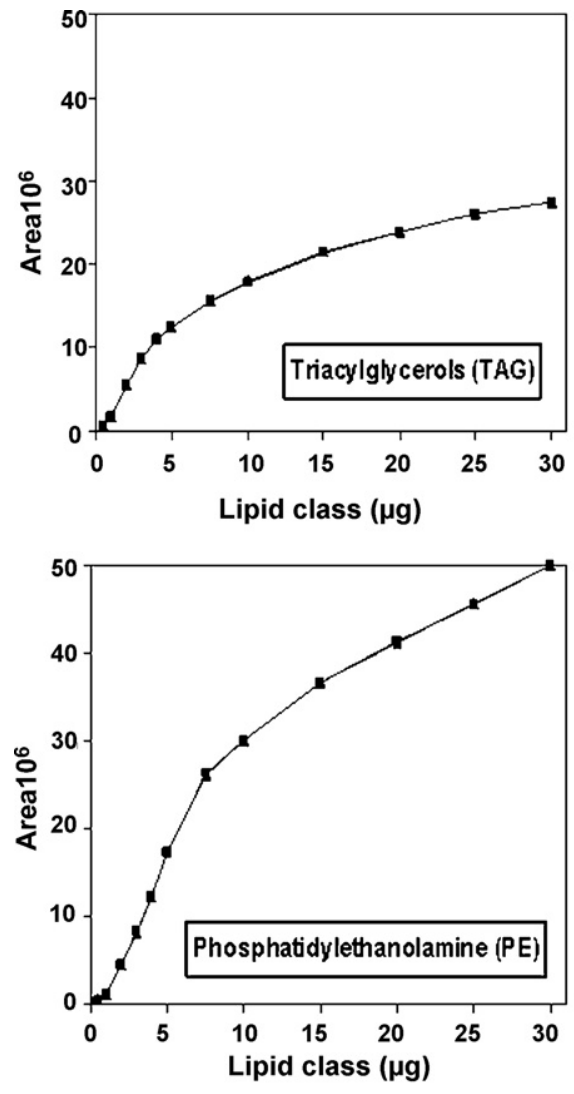

cially of the neutral lipids. The change of solvent is also required to avoid micelle formation and loss in separation efficiency for neutral lipids.

Using a monolithic normal phase HPLC column for the separation of lipid components with a broad range of polarities, some basic rules have to be considered since the gradient programme starts with a nonpolar solvent mixture and ends with a polar solvent, containing $15 \%$ of water. Because of the high water content at the end of the run a thorough equilibration has to be carried out by washing the column with solvent A for $10 \mathrm{~min}$ at a flow of $3 \mathrm{~mL} / \mathrm{min}$. The equilibration status holds for $1 \mathrm{~h}$, after which diffusion processes inside the column will change the chromatographic behaviour and thus alter retention times, especially for the neutral lipid components. For longer times a new equilibration step is recommended by running the full gradient programme.
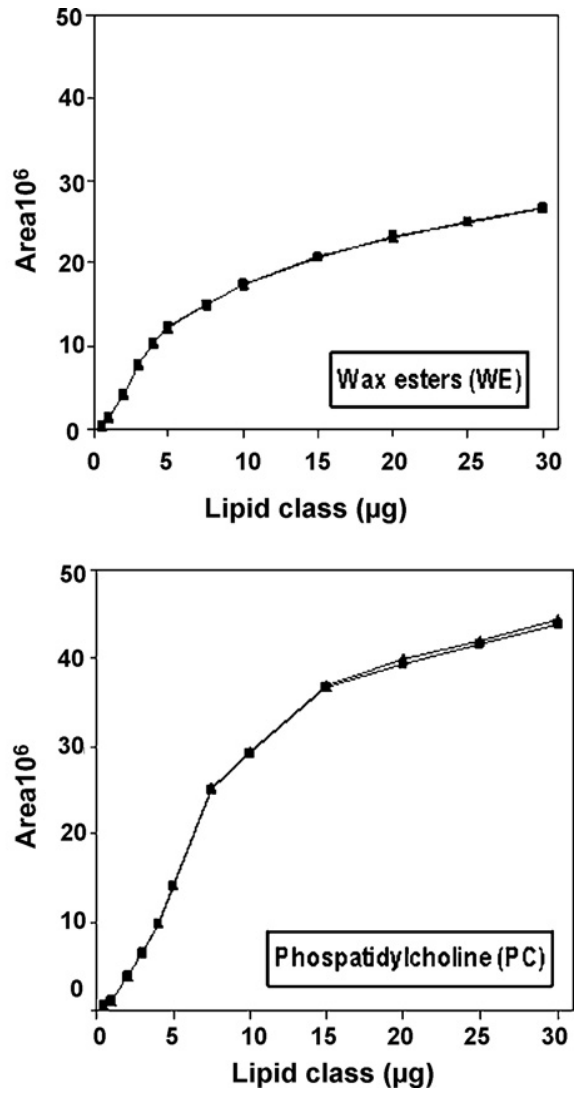

Fig. 1. Calibrations curves of selected neutral and polar lipids. 
Lipids of marine zooplankton have a large variety of individual components. Extremely non-polar compounds, like squalene from shark tissue, have to be separated from more polar wax esters or sterol esters, which are eluted directly after squalene. Furthermore, it is often necessary to separate fatty acid methylesters (e.g. 19:0 FAME), which closely follow wax esters. Odd-chain length FAME are usually added to samples before lipid extraction as internal standards for the quantification of fatty acids analyzed by gas chromatography. Finally, individual phospholipids have to be separated including lysophospholipids (Fig. 2).

Because lipid classes of some species have a wide concentration range (copepods contain up to $90 \%$ of wax esters but only $5-10 \%$ of total polar lipids), overloading of the column with neutral lipids is sometimes required for quantifying polar lipids. The macropore structure of the monolithic silica rod allows this overloading, and therefore additional separation steps can be avoided. For the same reason, a wide mass range for calibration from 0.5 to $30 \mu \mathrm{g}$ for neutral lipids and 1 to $60 \mu \mathrm{g}$ for phospholipids was used. For these lipid masses, the response characteristic of the ELSD, the response of which varies with lipid type, does not achieve a linear or polynomic fit [21,22], and therefore a point to point fit included in the EzChromElite software with 12 different concentrations was applied [9] (Fig. 1). The reproducibility of detector response and retention times was tested with two standard mixtures (1.0 and $4.0 \mu \mathrm{g} / \mu \mathrm{L} ; 10$ injections) (Table 2). \%RDS values indicate this method is sufficiently stable.

The separation of lipid classes shows clear differences among marine zooplankton species (Fig. 3). Copepods consist mainly of wax esters ranging from $80 \%$ to $95 \%$ of total lipids and low proportions of phosphatidylcholine and phosphatidylethanolamine (Fig. 3A, Table 3). Euphausiids have more varying lipid classes. Within the neutral lipids high percentages of wax esters, triacylglycerols and sterols were detected accounting for 30, 50 and $10 \%$, respectively. The polar lipids were also dominated by phosphatidylcholine (50\%) and phosphatidylethanolamine (10\%) (Fig. 3B, Table 3). The lipid class composition of the pteropod Clione

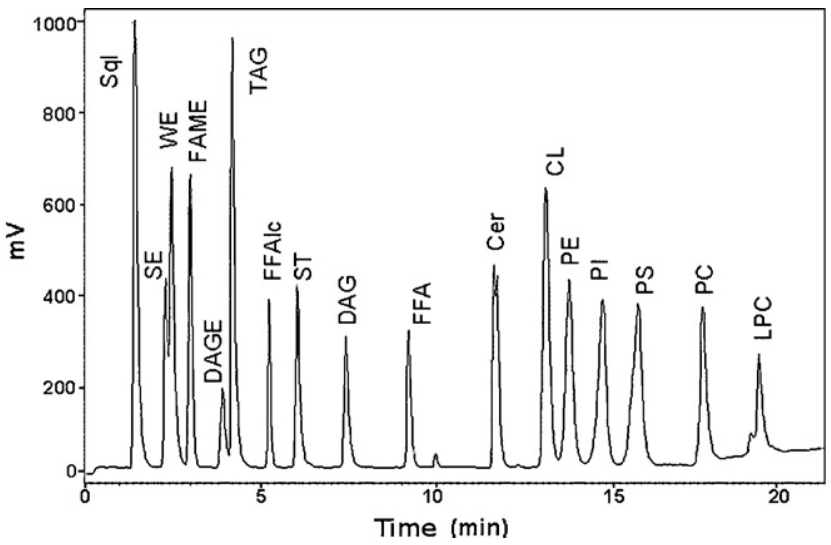

Fig. 2. Separation of neutral and polar lipid standards. Squalene (Sql), sterol ester (SE), wax ester (WE), nonadecanoic acid methylester (FAME), diacylglycerol ethers (DAGE), trioleate (TAG), oleyl alcohol (FFAlc), cholesterol (ST), diacylglycerol (DAG), palmitic acid (FFA), cerebrosids (Cer), cardiolipine $(\mathrm{Cl})$, phosphatidylethanolamine (PE), phosphatidylinositol (PI), phosphatidylserine (PS), phosphatidylcholine (PC), lysophosphatidylcholine (LPC).

limacina has a unique lipid composition with high proportions of diacylglycerol ethers (45\%) and triacylglycerols (40\%) (Fig. 3C, Table 3). In spite of the small structural differences in molecular weight and polarity both components can be separated by the chromatographic method. The ctenophore Mertensia ovum shows of a broad range of neutral lipids: wax esters, triacylglycerols, sterols and free fatty alcohols (Fig. 3D, Table 3). The occurrence of free fatty alcohols is unique for a marine zooplankter. They probably derive from digestion of dietary wax esters, which are cleaved into free fatty alcohols and fatty acids. Graeve et al. [23] have shown that this fraction is predominated by one long chain alcohol, 22:1(n-11). Phosphatidylcholine is the major phospholipid of M. ovum comprising $21.4 \%$ of total lipids.
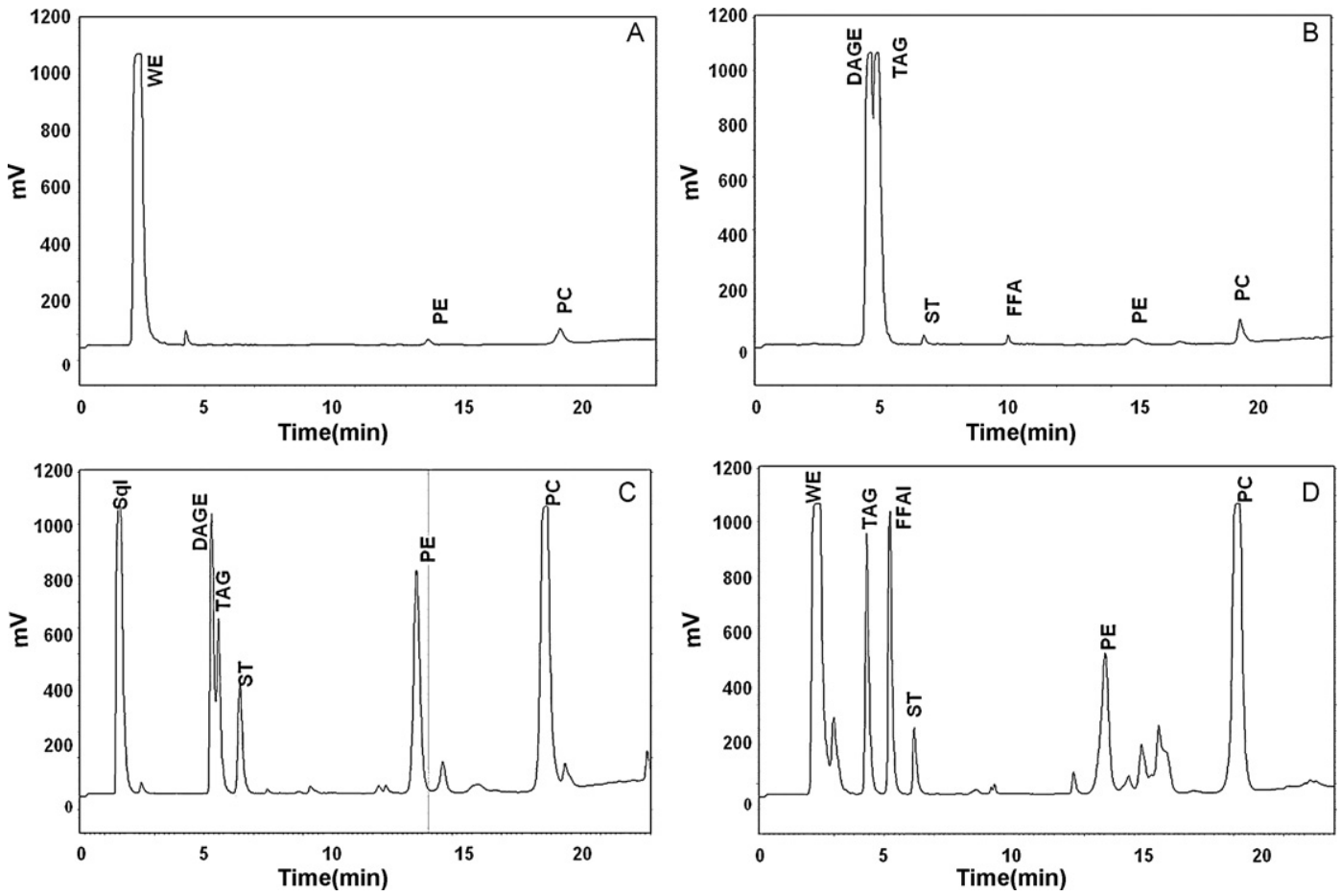

Fig. 3. Separation of lipid classes of various zooplankton taxa. Copepods (A), euphausiids (B), pteropods (C) and ctenophores (D), for abbreviations refer to Fig. 2. 
Table 3

Lipid class compositions of the various zooplankton taxa as mass\% of total lipids; NL, neutral lipids; PL, polar lipids, for abbreviations of lipid classes refer to Fig. 2.

\begin{tabular}{lcccc}
\hline Lipid classes & $\begin{array}{c}\text { Copepods } \\
\text { Mean } \pm \text { SD }\end{array}$ & $\begin{array}{c}\text { Euphausiids } \\
\text { Mean } \pm \text { SD }\end{array}$ & $\begin{array}{c}\text { Pteropods } \\
\text { Mean } \pm \text { SD }\end{array}$ & $\begin{array}{c}\text { Ctenophores } \\
\text { Mean } \pm \text { SD }\end{array}$ \\
\hline WE & $88.8 \pm 3.8$ & $23.1 \pm 7.7$ & $0.3 \pm 0.3$ & $48.9 \pm 30.9$ \\
DAGE & $0.3 \pm 0.4$ & $0.4 \pm 0.5$ & $44.9 \pm 5.1$ & $0.1 \pm 0.1$ \\
TAG & $1.9 \pm 0.7$ & $8.0 \pm 0.0$ & $40.2 \pm 5.1$ & $2.3 \pm 3.3$ \\
FFAlc & $2.9 \pm 3.3$ & $1.6 \pm 2.3$ & $3.0 \pm 2.2$ & $9.4 \pm 9.4$ \\
FFA & $0.4 \pm 1.1$ & $1.1 \pm 0.6$ & $1.3 \pm 0.9$ & $0.1 \pm 0.2$ \\
Sterols & - & $3.9 \pm 0.5$ & $1.2 \pm 0.4$ & $2.2 \pm 1.5$ \\
Cer & - & - & $0.3 \pm 0.5$ & $0.0 \pm 0.1$ \\
CL & $0.4 \pm 1.2$ & $1.1 \pm 0.9$ & $0.0 \pm 0.1$ & $0.5 \pm 0.3$ \\
PE & $0.8 \pm 0.5$ & $9.7 \pm 0.6$ & $1.2 \pm 0.5$ & $9.6 \pm 6.3$ \\
PI & $0.0 \pm 0.1$ & $0.5 \pm 0.2$ & $0.5 \pm 0.5$ & $2.7 \pm 3.9$ \\
PS & $1.0 \pm 1.6$ & $0.6 \pm 0.3$ & $0.1 \pm 0.2$ & $2.5 \pm 1.6$ \\
PC & $3.9 \pm 1.6$ & $50.4 \pm 10.8$ & $7.3 \pm 2.5$ & $21.4 \pm 14.6$ \\
LPC & - & - & - & $0.4 \pm 0.7$ \\
NL & $94.3 \pm 2.8$ & $37.9 \pm 9.3$ & $90.8 \pm 3.6$ & $63.2 \pm 24.3$ \\
PL & $5.7 \pm 2.8$ & $62.1 \pm 9.3$ & $9.3 \pm 3.6$ & $36.8 \pm 24.3$ \\
\hline
\end{tabular}

In summary, the method presented here is robust and sensitive for separation and quantification of major neutral and polar lipid classes found in marine animals. With an optimized solvent system and gradient programme we were able to achieve a complete separation of neutral and polar lipid classes. Additional steps to separate neutral from polar lipids before HPLC analysis were not necessary although concentrations of lipid classes can be highly different. No substantial increase of the working pressure (3.200 kPa) was observed, even after more than 1200 injections. Our method is also suitable for the analysis of lipids from other biological material, e.g. liver, gonads and muscles of fish (cod, salmon) and shark, micro- and macro-algae, as well as beef muscles.

\section{Acknowledgements}

The authors thank Gerhard Kattner, and two anonymous referees for their helpful comments on the manuscript. We are also grateful to Mrs. Annika Schröer for excellent technical assistance.

\section{References}

[1] R.F. Lee, W. Hagen, G. Kattner, Mar. Ecol. Progr. Ser. 307 (2006) 273.

[2] J. Dalsgaard, M. St. John, G. Kattner, D. Müller-Navarra, W. Hagen, Adv. Mar. Biol. 46 (2003) 225.

[3] H. Saito, M. Murata, Mar. Ecol. Progr. Ser. 168 (1998) 21

[4] R.E. Olsen, R.J. Henderson, J. Exp. Mar. Biol. Ecol. 129 (1989) 189.

[5] B.J. Bergen, J.G. Quinn, C.C. Parrish, Environ. Toxicol. Chem. 19 (2000) 2189.

[6] E.D. Hudson, R.J. Helleur, C.C. Parrish, J. Chromatogr. Sci. 39 (2001) 146

[7] W.W. Christie, J. Lipid Res. 26 (1985) 507.

[8] R. Homan, M.K. Anderson, J. Chromatogr. B 708 (1998) 21.

[9] J. Nordbäck, E. Lundberg, W.W. Christie, Mar. Chem. 60 (1998) 165.

[10] F.S. Deschamps, P. Chaminade, D. Ferrier, A. Baillet, J. Chromatogr. A 928 (2001) 127.

[11] C. Silversand, C. Haux, J. Chromatogr. B 703 (1997) 7.

[12] B. Sas, E. Peys, M. Helsen, J. Chromatogr. A 864 (1999) 179.

[13] T. Ikegami, N. Tanaka, Curr. Opin. Chem. Biol. 8 (2004) 527.

[14] N. Tanaka, H. Kobayashi, K. Nakanishi, H. Minakuchi, N. Ishizuka, Anal. Chem. 73 (2001) 420A.

[15] N. Tanaka, H. Kobayashi, N. Ishizuka, H. Minakuchi, K. Nakanishi, K. Hosoya, T. Ikegami, J. Chromatogr. A 965 (2002) 35.

[16] A. Jakab, E. Forgács, Chromatogr. Suppl. 56 (2002) S69.

[17] J.-F. Merlin, J. Gresti, S. Bellenger, M. Narce, Anal. Chim. Acta 565 (2006) 163.

[18] S. Altmaier, K. Cabrera, J. Sep. Sci. 31 (2008) 2551.

[19] Folch, et al., J. Biol. Chem. 226 (1957) 497.

[20] R. Skudas, B.A. Grimes, M. Thommes, K.K. Unger, J. Chromatogr. A 1216 (2009) 2625.

[21] M. Dreux, M. Lafosse, L. Morin-Allory, LC-GC 9 (1996) 148.

[22] C.S. Young, J.W. Dolan, LC-GC Eur. 17 (2004) 192.

[23] M. Graeve, M. Lundberg, M. Böer, G. Kattner, H. Hop, S. Falk-Petersen, Mar. Biol. 153 (2008) 643 